(C) О.А. Зыкина

\title{
ВОСПРИЯТИЕ ОБЩЕГРАЖДАНСКИХ ЦЕННОСТЕЙ СТУДЕНТАМИ МОСКВЫ И КИРОВСКОЙ ОБЛАСТИ*
}

В коние 2020 г. в рамках исследования восприятия общегражданских иченностей и российской идентичности было проведено анкетирование студенческой молодежи Москвы и Кировской области. В качестве оснований для гордости за свою страну рассматривались представления молодых людей об объектах культурного и природного наследия России, значимых исторических событиях и текущих направлениях деятельности нашего государства. В перечень объектов культурного достояния, по мнению учащихся, входят: особенности языка и речи, эпос народов России, народнье промысль, предметы быта, блюда начиональной кухни. В список важнейших памятников природы, как считают наши респонденты, следует включить: Байкал, Алтай, Камчатку и Карелию. Подавляющее большинство опрошенных в первую очередь гордится победой в Великой Отечественной войне и достижениями советской космонавтики. По результатам работы может быть сделан вывод о первостепенной значимости научных открытий, культурных и спортивных событий для возникновения патриотических чувств у современной студенческой молодежи. При сохранении единства мнений о наиболее принципиальных российских ценнностях в массовом сознании молодежи одновременно присутствуют различия в выборе ответов в зависимости от территории проживания. Это может свидетельствовать об особенностях политических настроений, реакций на внешние угрозы, ориентаций на первоочередное участие в проектах регионального или государственного уровней, которые свойственны для молодых людей каждого конкретного региона. На разнииу в суждениях студентов в определенной степени могут также влиять содержание учебных программ и качество образования столичных и провинциальных вузов.

Ключевые слова: студенческая молодежь; гражданские иенности; культурное и природное наследие; историческое самосознание; российская идентичность; региональная специфика; Москва; Кировская область

Ссылка при цитировании: Зыкина O.A. Восприятие общегражданских ценностей студентами Москвы и Кировской области // Вестник антропологии, 2021. № 4. С. 37-48.

Зыкина Ольга Александровна - младший научный сотрудник отдела русского народа, Институт этнологии и антропологии им. Н.Н. Миклухо-Маклая РАН (Российская Федерация, 119334, Москва, Ленинский пр., 32А). Эл. почта: ol_ya_z@mail.ru

* Выполнено в рамках Программы фундаментальных и прикладных научных исследований «Этнокультурное многообразие российского общества и укрепление общероссийской идентичности» по проекту «Российские ценности и символы: национальное единство и этнокультурное многообразие». 
С появлением наций-государств современного типа, характеризующихся культурной гетерогенностью населения и одновременно сохраняющих территориальную целостность и гражданско-политическую общность, неизбежно возникает вопрос о механизмах социальной консолидации жителей страны. Процесс формирования единой нации является непрерывным, динамичным и двусторонним. Государство в лице политической и интеллектуальной элит формулирует национальную идею, выстраивает государственную национальную политику; в свою очередь граждане соотносят себя с нацией, ведут свою деятельность сообразно своим представлениям о личных и групповых интересах, наполняют конкретным содержанием абстрактные термины и лозунги. Постоянная трансформация общества, усложнение его внутренней структуры и институтов, а также изменение внутренних и внешних условий развития страны требуют от каждого из акторов нациестроительства усилий для сохранения идентичности: корректировки соответствующих образов и понятий, продуцирования новых смыслов.

Концепт российской нации становится востребованным после распада СССР и образования Российской Федерации; к началу 2000-х он оформляется и присутствует в общественном и политическом дискурсе (Дробижева 2013: 42; Тишков 2013: 3), разрабатывается в научной среде (Тишков 2021; Тишков, Филиппова 2016: 3-18; Тишков 2011; Тишков 2013). Динамика национального самосознания у россиян, его содержательное наполнение, иерархия идентичностей, смыслы и ценности, на которые опирается российская гражданская идентичность, последовательно изучались в ходе социологических опросов и специальных научных изысканий (Горшков, Tuхонова 2005; Гориков 2016: 299-314; Горшков, Петухов 2018: 194-216; Дробижева 2013; Тишков 2011; Тишков 2013; Тишков, Бараш, Степанов 2014; Тишков 2021). Тем не менее, все еще сохраняет свою значимость вопрос о критериях, позволяющих говорить о российском народе как о единой общности. В этой связи представляется актуальным всестороннее изучение общей для всех граждан системы ценностей.

Одной из наиболее восприимчивых к социальным проблемам групп населения может считаться студенческая молодежь. Она довольно часто выступает активным агентом перемен в обществе, а потому стабильно становится предметом пристального внимания ученых самых разных научных специализаций. Социологические и антропологические исследования молодежи, проводимые университетами и академическими институтами, подчинены задачам выяснения ценностного профиля молодых граждан, определения их жизненных ориентиров и целей, демонстрируют переломные тренды в ценностных установках молодежи (Гориков, Шереги 2020; Тишков, Бараш, Степанов 2014). Свойственная молодому возрасту чувствительность к проблематике, связанной с национальной и этнической идентичностью, дает возможность для получения эмпирических данных, нацеленных на выявление комплекса общегражданских ценностей молодых людей и последующий анализ региональной специфики его распространения в студенческой среде.

\section{Характеристика выборочной совокупности}

В 2020 г. в рамках изучения восприятия общегражданских ценностей и российской идентичности учащейся молодежью был проведен опрос среди студентов Москвы и Кировской области. В Москве были опрошены студенты разных факультетов и направлений обучения нескольких крупнейших вузов страны: МГУ им. М.В. Ломоносова, РНИМУ им. Н.И. Пирогова, МГТУ им. Н.Э. Баумана, РГГУ, РАНХиГС, 
ГАУГН. Итоговая выборка включает 200 анкет, из них 77 (39\%) заполнены юношами и 123 (62\%) - девушками. В Кирове опрос проводился среди учащихся ВятГУ и КирГМУ. В результате были получены 218 анкет, респондентами стали 87 (40\%) юношей и 131 (60\%) девушка. Согласно квоте, мнение студентов социогуманитарных и естественно-научных специальностей представлено в равных долях. С учетом не только разнообразия получаемых студентами профессий, но и существенных различий по конкурсу и итоговому проходному баллу при поступлении, а также принимая во внимание формирование выборочной совокупности по принципу случайного отбора, обе выборки могут оцениваться как сбалансированные.

Вопрос о национальности не был обязательным при анкетировании, тем не менее, подавляющее большинство респондентов - 82\% (163 чел.) в Москве и 75\% (164 чел.) в Кирове - дали на него ответ. Из них в Кирове 85\% (140 чел.) указывают принадлежность только к одному этносу, остальные $15 \%$ (24 чел.) - к двум, что сопоставимо со средним значением по стране - население с множественной этнической идентичностью в России оценивается в 10-15\% (Степанов 2019: 152-153). В московской выборке доля лиц, относящих себя к нескольким этносам, выше: 22\% (36 чел.) против $78 \%$ (127 чел.). Этнический состав столичных респондентов выглядит следующим образом: 92\% - русские, по 4\% - евреи и украинцы, по 3\% - белорусы и татары. Среди других национальностей названы армяне, башкиры, буряты, греки, грузины, китайцы, коми, корейцы, марийцы, молдаване, немцы, осетины, поляки, сербы, черкесы, чеченцы, чуваши. Этнический состав участников опроса в целом соотносится с этническим составом жителей г. Москвы по результатам переписи 2010 года. Опрошенные студенты г. Кирова по этническому составу также показали близкую к фактической для всего населения картину: 96\% - русские, $2 \%$ - россияне, по 3\% - коми, удмурты и украинцы, присутствуют - татары, азербайджанцы, армяне, марийцы, немцы ${ }^{1}$. Ответы на вопросы о родном языке свидетельствуют о том, что множественная языковая идентичность встречается заметно реже, чем этническая. Только 5\% опрошенных обозначили родными два языка, одним из которых всегда был русский. Считают своим единственным родным нерусский язык $2 \%$ кировских студентов и $2,5 \%$ московских, однако, половина из них в повседневной жизни общаются только на русском языке. В целом называют родным языком русский 98\% респондентов в Москве и 95\% в Кирове.

Процессы осознания гражданской, этнической и региональной идентичностей студентами могут быть представлены на основе анализа данных по ответам на вопрос «Как Вас должны воспринимать окружающие в повседневной жизни - как гражданина России, или как представителя отдельной национальности, или как жителя определённого региона?». При этом имелась возможность выбрать несколько вариантов ответа и отразить различные сочетания идентичностей. Подавляющее большинство участников опроса выразили желание, чтобы их воспринимали как граждан страны (68\% в Москве и $81 \%$ в Кирове), причем чаще всего это был единственный ответ. Значимость для своей самоидентификации этнической составляющей отметили $17 \%$ респондентов в Москве и $6 \%$ - в Кирове, но только для трети из

${ }^{1}$ Согласно материалам Всероссийской переписи населения 2010 г. среди жителей г. Москвы, указавших свою национальную принадлежность, представители русского этноса составляют $91,65 \%$, украинцев $-1,42 \%$, татар $-1,38 \%$, армян $-0,98 \%$, евреев $-0,49 \%$, белорусов $-0,36 \%$. По г. Кирову национальный состав выглядит следующим образом: русские $-96,65 \%$, татары $0,79 \%$, украинцы $-0,57 \%$, марийцы - 0,31\%, удмурты - 0,29\%, коми $-0,08 \%$ (Всероссийская перепись населения 2010). 
них это был единственный вариант ответа. Важность региональной идентичности подчеркнули 14\% опрошенных в Москве и 11\% - в Кирове. К возможности выбрать несколько вариантов ответа прибегли около $15 \%$ участников опроса в Москве и $12 \%$ - в Кирове, практически все они в качестве одной из характеристик называли гражданскую идентичность и сочетали ее либо с этнической, либо с региональной идентичностью, а в ряде случаев - с обеими одновременно.

Бо́льшая часть студентов, принявших участие в исследовании, проживают в городе с рождения: $64 \%$ в Москве и $75 \%$ в Кирове. Приехали из других регионов России в столицу $32 \%$ опрошенных, в Киров - $23 \%$; прибыли из-за рубежа в Москву - 4\%, в Киров - $1 \%$. Материалы опроса подтверждают, что в столичные вузы поступают молодые люди из самых разных уголков нашей страны от Крыма до Сахалина и от Калмыкии до Мурманска, состав регионов выбытия предельно многообразен и включает все федеральные округа Российской Федерации. В Кировскую область с целью получения высшего образования переезжают в первую очередь выходцы из сопредельных территорий - Республики Коми (39\%), Удмуртской республики (10\%), Костромской области $(10 \%)$, Архангельской области (4\%), Нижегородской области (4\%), Вологодской области (2\%), Пермского края (2\%). Кроме того, более половины приезжих студентов прибыли из северных регионов, среди которых помимо уже названных встречались Ненецкий, Ямало-Ненецкий, Ханты-Мансийский автономные округа и Мурманская область.

Вопросы, касающиеся трудоустройства и общего материального положения респондентов, свидетельствуют о том, что студенческая молодежь как Москвы, так и Кирова в основном еще не работает и с проблемами в этой сфере не сталкивалась. Совмещают работу и учебу около четверти опрошенных студентов, чаще всего это учащиеся старших курсов. Оценивают свое благосостояние как нормальное чуть менее половины молодых людей. Разница в самоощущении между столичными и провинциальными студентами проявляется через две противоположные категории материального положения - «хорошее» и «затруднительное». Сообщают о трудностях четверть учащихся московских вузов и треть кировчан, о хорошем благосостоянии готовы говорить $20 \%$ опрошенных в Москве и только $12 \%$ - в Кирове.

\section{Культурное наследие и природные богатства нашей страны}

Природа и культура в своей совокупности определяют среду обитания человека, являются необходимым условием существования любого сообщества. Культура и природные богатства неизменно становятся одним из важнейших оснований для гордости за свою страну у россиян ${ }^{1}$. В рамках текущего исследования с целью изучения представлений молодежи относительно общегражданских ценностей в их материальном воплощении были рассмотрены информированность студентов об объектах культурного и природного наследия России и интерес к ним.

В ходе анкетирования студентам предлагалось оценить необходимость создания общего списка культурного наследия нашей страны. в поддержку формирования такого перечня выступили практически все участники опроса за исключением воздержавшихся от ответа; обозначили отрицательное отношение к подобной инициативе только $3 \%$ опрошенных в столице и $4 \%$ - в Кирове. Исходя из этого можно говорить

1 По данным опросов Левада-центра в 2014-2016 гг. иерархия представлений об основаниях национальной гордости очень устойчива. Возглавляют список позиций, внушающих респондентам чувство гордости за Россию: российская история (44\%), природные богатства (38\%), вооруженные силы (36\%), российская культура (34\%) (Левада-центр 2016). 
о высокой значимости для молодежи сохранения и приумножения объектов российской культуры. К сожалению, готовы были внести свои предложения к списку чуть менее $30 \%$ респондентов, но и полученных данных достаточно, чтобы выделить наиболее важные по мнению молодых людей культурные явления. В первую очередь к культурным ценностям были отнесены: особенности языка и речи, о них говорят $21 \%$ опрошенных в Москве и $17 \%$ - в Кирове; народные промыслы - 9\% и 25\%; предметы быта (игрушки, музыкальные инструменты, костюм и др.) - 17\% и 9\%; блюда национальной кухни - $28 \%$ и 5\%; эпос народов России - $32 \%$ и 5\%; памятники архитектуры - 15\% и $11 \%$; места памяти $-21 \%$ и $9 \%$. В этом же ряду были перечислены памятники природы регионального значения, их вспомнили 5\% ответивших московских студентов и $22 \%$ - кировских.

Наиболее известные природные объекты России нашли свое отражение в ответах на вопрос об интересных направлениях туристических поездок. Первое место в рейтинге, составленном самими респондентами, занимает озеро Байкал - его называют $25 \%$ из числа предложивших свой вариант студентов в Москве и $32 \%$ - в Кирове 1 . Среди других достопримечательностей, которые мечтают посетить молодые люди, часто звучат: Алтай, его указали $25 \%$ ответивших в Москве и $10 \%$ - в Кирове; Камчатка и Карелия - по 19\% и 9\% в Москве и Кирове соответственно; Крым - 9\% и $12 \%$; Дальний Восток и, в частности Владивосток - 9\% и 7\%. В этом же списке идут следующие желаемые для путешествий города: Санкт-Петербург, настроены на его посещение $13 \%$ москвичей и $25 \%$ кировчан; Казань и Калининград по 9\% и 7\% в Москве и Кирове соответственно. Кроме того, в ответах московских студентов нередко упоминается Кавказ, а в ответах кировских - Москва и Сочи.

\section{Значимые события российской истории}

Отношение к прошлому своей страны является важной составляющей государственной самоидентификации человека. Анализ полученного спектра наиболее значительных событий российской истории позволяет обрисовать общий для молодых людей круг взглядов и ценностей, выделить ключевые образы и установки их социально-исторического миропонимания. Подавляющее большинство респондентов в первую очередь гордится победой в Великой Отечественной войне и технологическим прорывом советской космонавтики (табл. 1). Согласно опубликованным материалам Института социологии РАН - именно эти события возглавляют рейтинг исторических достижений России ${ }^{2}$, что подтверждает результаты текущего опроса и дает возможность для сравнительных исследований. Другие предложенные в анкете

\footnotetext{
1 Эти данные могут быть соотнесены с опросом ВЦИОМ 2013 г., согласно которому озеро Байкал посчитали одним из главных символов России 20\% респондентов (ВЦИОМ 2013).

${ }^{2}$ Массовые опросы жителей России по данной теме проводились ИС РАН в 1998, 2008 и 2016 гг. и охватывали все категории населения. Наблюдалась волнообразная динамика по доле респондентов, рассматривающих те или иные события в качестве предмета национальной гордости, с уменьшением значений почти по всем вариантам ответов в 2008 г. и последующим увеличением при новом измерении. В 2016 г. Победу в Великой Отечественной войне выбрали предметом гордости 76\% опрошенных, полет в космос Ю. Гагарина - 46\% (Горшков, Петухов 2018: 187). Следует отметить, что по данным текущего опроса студенческой молодежи конца 2020 года достижения советской космонавтики актуализированы заметно в большей степени. В том числе, это может быть связано с близостью юбилея первого полета человека в космос в 2021 г. и разработкой российской вакцины от коронавируса под торговой маркой «Спутник $\mathrm{V}$ », что способствовало дополнительной популяризации событий в истории освоения космоса.
} 
события прошлого века определялись студентами в качестве значимых существенно реже. Чувствуют гордость в связи с преодолением последствий сталинских репрессий только четверть опрошенных молодых людей. Исторические факты, такие как Октябрьская революция 1917 г., образование СССР и его противостояния военному блоку НАТО в годы холодной войны, принятие Россией международных обязательств СССР после его распада - находят поддержку в среднем не более чем у $15 \%$.

Сопоставление данных по регионам дает более подробную и многоплановую картину сложившегося исторического самосознания у молодежи. Московские студенты склонны придавать бо́льшее значение Октябрьской революции 1917 г. и событиям в истории освоения космоса, чем их сверстники из Кирова. В свою очередь учащиеся кировских вузов несколько чаще подчеркивают значимость правопреемственности России после распада СССР.

Таблица 1

Какие исторические события прошлого века вызывают у Вас чувство гордости за Россию, 2020 г., (допускалось несколько ответов)

\begin{tabular}{|c|c|c|c|c|c|c|}
\hline & \multicolumn{3}{|c|}{ Москва } & \multicolumn{3}{|c|}{ Киров } \\
\hline & 总 & $\partial^{0}$ & 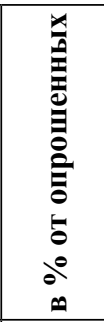 & 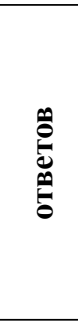 & $\stackrel{\partial}{\theta}$ & 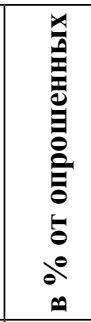 \\
\hline $\begin{array}{l}\text { 0). Если нет таких событий, } \\
\text { отметьте только данный пункт }\end{array}$ & 13 & $3 \%$ & $7 \%$ & 12 & $2 \%$ & $6 \%$ \\
\hline 1). Октябрьская социалистическая революция 1917 г. & 27 & $5 \%$ & $14 \%$ & 20 & $4 \%$ & $9 \%$ \\
\hline $\begin{array}{l}\text { 2). Образование Союза Советских Социалистических } \\
\text { Республик в } 1922 \text { г. }\end{array}$ & 24 & $5 \%$ & $12 \%$ & 27 & $5 \%$ & $12 \%$ \\
\hline $\begin{array}{l}\text { 3). Разгром гитлеровской Германии и победа Совет- } \\
\text { ского Союза в Великой Отечественной войне } \\
\text { 1941-1945 гг. }\end{array}$ & 147 & $30 \%$ & $74 \%$ & 164 & $32 \%$ & $75 \%$ \\
\hline 4). Преодоление последствий сталинских репрессий & 52 & $11 \%$ & $26 \%$ & 50 & $10 \%$ & $23 \%$ \\
\hline $\begin{array}{l}\text { 5). Противостояние Советского Союза } \\
\text { военному блоку НАТО в годы холодной войны }\end{array}$ & 30 & $6 \%$ & $15 \%$ & 32 & $6 \%$ & $15 \%$ \\
\hline $\begin{array}{l}\text { 6). Запуск первого в мире спутника и } \\
\text { первый полет человека в космос }\end{array}$ & 155 & $31 \%$ & $78 \%$ & 158 & $31 \%$ & $72 \%$ \\
\hline $\begin{array}{l}\text { 7). Россия приняла на себя международные обяза- } \\
\text { тельства и стала правопреемником СССР } \\
\text { после его распада }\end{array}$ & 24 & $5 \%$ & $12 \%$ & 38 & $7 \%$ & $17 \%$ \\
\hline 8). Другое (напишите) & 15 & $3 \%$ & $8 \%$ & 2 & $0 \%$ & $1 \%$ \\
\hline \multirow[t]{2}{*}{ 9). Затрудняюсь ответить } & 7 & $1 \%$ & $4 \%$ & 12 & $2 \%$ & $6 \%$ \\
\hline & 494 & $100 \%$ & $247 \%$ & 515 & $100 \%$ & $236 \%$ \\
\hline
\end{tabular}




\section{Современные события и направления деятельности российского государства}

Одним из индикаторов гармоничного взаимодействия общества и государства является одобрительная реакция населения на проводимые властью социально-экономические реформы. Восприятие молодыми людьми современных российских реалий накладывает свой отпечаток на формирование у них государственной идентичности и активной гражданской позиции. В рамках изучения общероссийских ценностных ориентаций молодого поколения респондентам предлагалось выбрать ключевые события и направления деятельности государства, вызывающие чувство гордости за свою страну. В списке возможных вариантов ответов были перечислены результаты государственной политики России одновременно по нескольким сферам жизни общества, включая конкретные примеры (табл. 2).

Самой высокой оценки по мнению студентов заслуживают отечественные достижения в области науки, культуры, искусства и спорта - к ним отсылают чуть менее половины всех участников опроса. В числе крупных успехов нашей страны были также названы: сохранение этнического многообразия и национальных языков; улучшение возможности профессионального обучения и роста для людей как молодого, так и пожилого возраста; развитие туризма в регионах; создание самого большого в мире атомного ледокольного флота; космические полеты. На основании этого можно говорить о первостепенной значимости научных открытий, культурных и спортивных событий для возникновения патриотических чувств у современной студенческой молодежи. В то же время, один из последних научных прорывов России - запуск в производство первой в мире вакцины от коронавируса - полноценной поддержки у студентов не нашел. Сложно сказать, имело ли здесь место общее скептичное отношение к современным российским научным и промышленным разработкам или же повлияла дискуссия в СМИ по поводу соблюдения всех процедурных моментов при регистрации вакцины.

Обращает на себя внимание сравнительно низкая оценка студентами достижений России в военной сфере. Доля лиц, испытывавших чувство гордости в связи с укреплением вооруженных сил и развитием военной техники, фактически в два раза меньше, чем это было по результатам содержательно близких массовых опросов 2016 года ${ }^{1}$. Тем не менее, случаи участия российской армии в ходе борьбы с международным терроризмом в Сирии и миротворческой миссии в Нагорном Карабахе, судя по ответам, могут быть отнесены в разряд успешных военных кампаний и рассматриваются скорее в позитивном ключе.

В процессе исследования были выделены наименее популярные в студенческой среде направления деятельности государства. В первую очередь вызывают негативную реакцию механизмы реализации политических прав и свобод граждан, среди них: прозрачная система голосования на выборах в органы власти, свобода слова и печати. Кроме того, пятая часть опрошенных студентов высказалась о современных достижениях России предельно критически, все они особых поводов для гордости в настоящее время не видят.

\footnotetext{
${ }^{1}$ По данным опроса Левада-центра считают поводом для гордости вооруженные силы $36 \%$ респондентов (Левада-центр 2016); по сведениям ИС РАН выбрали таким предметом российскую армию 35\% опрошенных (Гориков, Петухов 2018: 187).
} 
Таблица 2

Ниже вразброс перечислены современные события и направления деятельности государства. Какие из них вызывают у Вас чувство гордости за Россию, 2020 г., (допускалось несколько ответов)

Если нет таких событий, отметьте только данный пункт

Достижения в области науки, культуры, искусства и спорта

Сохранение этнического многообразия и

национальных языков

Создание самого большого в мире

атомного ледокольного флота

Развитие туризма в регионах России

Борьба с международным терроризмом,

в том числе в Сирии; миротворчество в Наг. Карабахе

Космические полеты

Улучшение возможности проф. обучения и роста для людей как молодого, так и пожилого возраста

Укрепление Вооруженных сил РФ

Борьба с безработицей и бедностью

Развитие военной техники

Празднование 75-летия Победы

в Великой Отечественной войне

Первая в мире вакцина от коронавируса

Многопартийность, свобода слова и печати

Пенсии, прожиточный минимум, здравоохранение с 2020 г. находятся под защитой Конституции

Прозрачная система голосования на выборах в органы власти

Другое (напишите)

Затрудняюсь ответить

\begin{tabular}{|c|c|c|c|c|c|}
\hline \multicolumn{3}{|c|}{ Москва } & \multicolumn{3}{|c|}{ Киров } \\
\hline $\begin{array}{l}\stackrel{\infty}{0} \\
\stackrel{0}{0} \\
\text { है }\end{array}$ & $\partial_{\infty}^{\theta}$ & 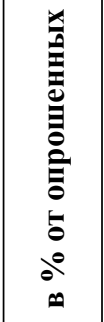 & 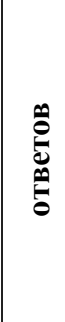 & $\partial_{\infty}^{\theta}$ & 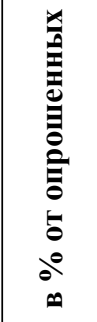 \\
\hline 39 & $6 \%$ & $20 \%$ & 45 & $6 \%$ & $21 \%$ \\
\hline 89 & $14 \%$ & $45 \%$ & 101 & $14 \%$ & $46 \%$ \\
\hline 56 & $9 \%$ & $28 \%$ & 55 & $8 \%$ & $25 \%$ \\
\hline 54 & $9 \%$ & $27 \%$ & 47 & $6 \%$ & $22 \%$ \\
\hline 51 & $8 \%$ & $26 \%$ & 44 & $6 \%$ & $20 \%$ \\
\hline 50 & $8 \%$ & $25 \%$ & 55 & $8 \%$ & $25 \%$ \\
\hline 48 & $8 \%$ & $24 \%$ & 49 & $7 \%$ & $22 \%$ \\
\hline 46 & $7 \%$ & $23 \%$ & 55 & $8 \%$ & $25 \%$ \\
\hline 34 & $5 \%$ & $17 \%$ & 37 & $5 \%$ & $17 \%$ \\
\hline 32 & $5 \%$ & $16 \%$ & 46 & $6 \%$ & $21 \%$ \\
\hline 29 & $5 \%$ & $15 \%$ & 44 & $6 \%$ & $20 \%$ \\
\hline 29 & $5 \%$ & $15 \%$ & 55 & $8 \%$ & $25 \%$ \\
\hline 27 & $4 \%$ & $14 \%$ & 31 & $4 \%$ & $14 \%$ \\
\hline 13 & $2 \%$ & $7 \%$ & 13 & $2 \%$ & $6 \%$ \\
\hline 10 & $2 \%$ & $5 \%$ & 18 & $2 \%$ & $8 \%$ \\
\hline 7 & $1 \%$ & $4 \%$ & 9 & $1 \%$ & $4 \%$ \\
\hline 4 & $1 \%$ & $2 \%$ & 6 & $1 \%$ & $3 \%$ \\
\hline 5 & $1 \%$ & $3 \%$ & 17 & $2 \%$ & $8 \%$ \\
\hline 623 & $100 \%$ & $312 \%$ & 727 & $100 \%$ & $333 \%$ \\
\hline
\end{tabular}


Активная гражданская позиция студенческой молодежи предполагает наличие интереса к общественной работе, готовность принимать посильное участие в различных событиях государственного уровня. Распределение ответов на вопрос о желании респондентов выступить на том или ином мероприятии в роли волонтера позволяет судить о потенциально наиболее востребованных направлениях в сфере социальной и культурной политики, а также дает новые сведения об иерархии ценностей молодых людей. Несомненной ценностью может считаться помощь лицам пожилого возраста или с ограниченными физическими возможностями, на нее настроены более 40\% опрошенных студентов как в Москве, так и в Кирове. Среди других предпочтительных к участию и значимых мероприятий следует назвать: крупные спортивные соревнования, выбрали этот вариант ответа 29\% учащихся в Москве и $43 \%$ - в Кирове; День Победы - 26\% и 44\% в Москве и Кирове соответственно; мероприятия по сохранению и развитию языков и культур народов России - 27\% и 15\%; мероприятия по продвижению русского языка и российской культуры - 20\% и 14\%; День города - $15 \%$ и $28 \%$.

\section{Заключение}

В результате исследования восприятия общегражданских ценностей и российской идентичности студентами Москвы и Кировской области был получен большой массив эмпирических данных. Характеристика выборочной совокупности позволяет представить текущий срез сочетания идентичностей в самосознании студенческой молодежи в категориях «гражданская - этническая - региональная». Подавляющее большинство столичных и кировских студентов позиционируют себя исключительно как граждан страны, о множественной территориальной идентичности сообщают не более $15 \%$ участников опроса. Описание этнокультурного состава учащихся вузов демонстрирует практически полное его совпадение с фактической картиной для всего населения в каждом из регионов.

В ходе работы в качестве одного из важнейших оснований для гордости за свою страну рассматривались представления об объектах культурного и природного наследия России. Поддержка подавляющим большинством студентов инициативы создания общего списка культурного наследия нашей страны указывает на важность для молодежи сохранения и приумножения объектов российской культуры. Чаще всего при этом имеются в виду: особенности языка и речи, эпос народов России, народные промыслы, предметы быта (игрушки, музыкальные инструменты, костюм и др.), блюда национальной кухни. Символами страны могут также выступать памятники природы регионального и государственного значения. В первую очередь, по мнению учащихся, в этот список попадают Байкал, Алтай, Камчатка и Карелия.

Как показал анализ исторического самосознания студентов Москвы и Кирова, при сохранении единства мнений о наиболее важных событиях отечественной истории в массовом сознании молодежи одновременно присутствуют различия в выборе ответов в зависимости от территории проживания. Это может свидетельствовать об особенностях политических настроений, реакций на внешние угрозы, ориентаций на первоочередное участие в проектах регионального или государственного уровней, которые свойственны для молодых людей каждого конкретного региона. На разницу в суждениях студентов в определенной степени могут также влиять содержание учебных программ и качество образования столичных и провинциальных вузов. 
Распределение ответов учащихся столичных и кировских вузов относительно ключевых событий и направлений деятельности государства, вызывающих чувство гордости за свою страну, позволяет сделать вывод о первостепенной значимости научных открытий, культурных и спортивных событий для возникновения патриотических чувств у современной студенческой молодежи. Кроме того, на основании полученного рейтинга событий российской реальности и популярных общенациональных мероприятий можно судить о наиболее успешных управленческих решениях в сфере социальной и культурной политики.

В целом, результаты социологического измерения представлений о культурном и природном наследии страны, значимых исторических событиях и современных направлениях деятельности государства являются эффективным инструментом социальной диагностики и могут иметь важное значение как для прогнозирования политического поведения населения, так и для понимания различных сегментов политической жизни.

\section{Источники и материалы}

Всероссийская перепись населения 2010 - Население по национальности и владению русским языком по субъектам Российской Федерации // Тома официальной публикации итогов Всероссийской переписи населения 2010 года. Т. 4. С. 94-95 [Электронный ресурс] // Федеральная служба государственной статистики (Росстат): [веб-сайт]. https:/gks.ru/ free_doc/new_site/perepis2010/croc/Documents/Vol4/pub-04-04.pdf C. 52-53; C.94-95 (дата обращения: 11.11.2021).

ВЦИОМ 2013 - Национальная гордость / Пресс-выпуски 30.06.2016 [Электронный ресурс] // Акционерное общество «Всероссийский центр изучения общественного мнения» (ВЦИOM): [веб-сайт]. https://wciom.ru/analytical-reviews/analiticheskii-obzor/simvoly-rossiinarodnyj-rejting (дата обращения: 11.11.2021).

Левада-центр 2016 - Символы России: народный рейтинг / Аналитический обзор 3 октября 2013 [Электронный ресурс] // Автономная некоммерческая организация Аналитический Центр Юрия Левады (АНО Левада-Центр): [веб-сайт]. https://www.levada.ru/2016/06/30/ natsionalnaya-gordost/ (дата обращения: 11.11.2021).

\section{Научная литература}

Горшков М.К. Российское общество как оно есть (опыт социологической диагностики). В 2 т. Т.1. Изд. 2-е, перераб. и доп. М.: Новый хронограф, 2016. 416 с.

Горшков М.К., Петухов В.В. (отв. ред.) Двадцать пять лет социальных трансформаций в оценках и суждениях россиян: опыт социологического анализа. М.: Весь Мир, 2018. 384 с.

Горшков М.К., Тихонова Н.Е. (отв. ред.) Российская идентичность в условиях трансформации: опыт социологического анализа. М.: Наука, 2005. 396 с.

Горшков М.К., Тихонова Н.Е. (отв. ред.) Столицы и регионы в современной России: мифы и реальность пятнадцать лет спустя. М.: Весь Мир, 2018. 312 с.

Горшков М.К., Шереги Ф.Э. Молодежь России в зеркале социологии. К итогам многолетних исследований. М.: ФНИСЦ РАН, 2020. 688 с.

Дробижева Л.М. (рук. проекта и отв. ред.) Гражданская, этническая и региональная идентичность: вчера, сегодня, завтра. М.: Российская политическая энциклопедия, 2013. 485 с.

Степанов В.В. Измерение культурного многообразия России // Измерение культурного многообразия. Языковая ситуация, переписи, полевая этностатистика / ред. М.Ю. Мартынова, В.В. Степанов. М.: ИЭА РАН, 2019. С. 140-154.

Тишков B.A. (под ред.) Российская нация: Становление и этнокультурное многообразие. М.: Наука, 2011. 462 c. 
Тишков В.А. Национальная идея России. М.: Издательство АСТ, 2021. 416 с.

Тишков B.A. Российский народ: история и смысл национального самосознания. М.: Наука, 2013. $649 \mathrm{c}$.

Тишков В.А. Филиппова Е.И. (отв. ред.) Культурная сложность современных наций. М.: Политическая энциклопедия, 2016. 384 с.

Тишков В.А., Бараш Р.Э., Степанов В.В. (под ред.) Российское студенчество: идентичность, жизненные стратегии и гражданский потенциал. М: ИЭА РАН, 2014. 342 с.

Zykina, Olga A.

\section{Perception of Civic Values by Students in Moscow and the Kirov Region}

\section{DOI: 10.33876/2311-0546/2021-4/37-48}

At the end of 2020, a students' survey in Moscow and Kirov region was conducted to study the perception of civic values and Russian identity. Young people's perceptions of Russia's cultural and natural heritage, significant historical events, and current activities of the state were examined as foundations for pride in their country. According to the students, the cultural heritage of Russia includes language and speech, epics of the peoples of Russia, folk crafts, household items, and national cuisine. The most important natural monuments as seen by students included Baikal, Altai, Kamchatka, and Karelia. The vast majority of respondents are primarily proud of the victory in the Great Patriotic War and the achievements of Soviet cosmonautics. The results revealed that scientific discoveries, cultural and sports events are of paramount importance for the patriotic feelings among the modern student youth. While the opinions on the most fundamental Russian values in the mass consciousness of young people mostly coincide, there are certain differences in the choice of answers depending on the territory of residence. This may indicate that political sentiments, reactions to external threats, and orientations towards participation in regional or state projects of young people differ in each region. To a certain extent, the students 'judgments can also be influenced by the curricula and the quality of education in metropolitan and provincial universities.

Keywords: student youth, civic values, cultural and natural heritage, historical identity, Russian identity, regional specificity, Moscow, Kirov region

For Citation: Zykina, O.A. 2021. Perception of Civic Values by Students in Moscow and the Kirov Region. Herald of Anthropology (Vestnik Antropologii) 4: 37-48.

Author Info: Zykina, Olga A. - junior researcher, Institute of Ethnology and Anthropology RAS (Moscow, Russia). E-mail: ol_ya_z@mail.ru

Funding: The research was carried out within the framework of the Program of fundamental and applied scientific research "Ethnocultural diversity of Russian society and strengthening of the all-Russian identity". The project "Russian values and symbols: national unity and ethno-cultural diversity".

\section{References}

Drobizheva, L.M., ed. 2013. Grazhdanskaya, etnicheskaya i regional'naya identichnost': vchera, segodnya, zavtra [Civil, ethnic and regional identities: yesterday, today, tomorrow]. Moscow: ROSSPEN.

Gorshkov, M.K. 2016. Rossiiskoe obshchestvo kak ono est' (opyt sotsiologicheskoi diagnostiki) [Russian society as it is (experience of sociological diagnosis)]. Vol. 1. Moscow: Novyi 
khronograf.

Gorshkov, M.K., Petukhov, V.V., eds. 2018. Dvadtsat' pyat' let sotsial'nykh transformatsii v otsenkakh i suzhdeniyakh rossiyan: opyt sotsiologicheskogo analiza [Twenty-five years of social transformations in the assessments and judgments of Russians: practices in sociological analysing]. Moscow: Ves' mir.

Gorshkov, M.K., Sheregi, F.E. 2020. Molodezh' rossii v zerkale sotsiologii. K itogam mnogoletnikh issledovanii [Russian youth in the mirror of sociology. To the results of many years of research.] Moscow: FNISC RAN publ.

Gorshkov, M.K., Tikhonova, N.E., eds. 2005. Rossiiskaya identichnost'v usloviyakh transformatsii: opyt sotsiologicheskogo analiza [Russian identity against the background of transformations: practices in sociological analysing]. Moscow: Nauka.

Gorshkov, M.K., Tikhonova, N.E., eds. 2018. Stolitsy $i$ regiony v sovremennoi Rossii: mify $i$ real'nost' pyatnadtsat' let spustya [Capitals and regions in modern Russia: myths and reality fifteen years later]. Moscow: Ves' mir.

Stepanov, V.V. 2019. Izmerenie kul'turnogo mnogoobraziya Rossii [Measuring the cultural diversity of Russia]. In Izmerenie kul'turnogo mnogoobraziya. Yazykovaya situatsiya, perepisi, polevaya etnostatistika [Measuring cultural diversity. Language situation, censuses, field ethnostatistics], edited by M.Yu. Martynova, V.V. Stepanov, 140-154. Moscow: IEA RAS.

Tishkov, V.A. 2013. Rossiiskii narod: istoriya i smysl natsional'nogo samosoznaniya [The Russian people: history and meaning of national identity]. Moscow: Nauka.

Tishkov, V.A. 2021. Natsional'naya ideya Rossii [National idea of Russia]. Moscow: AST.

Tishkov, V.A., Barash, R.E., Stepanov, V.V., eds. 2014. Rossiiskoe studenchestvo: identichnost', zhiznennye strategii i grazhdanskii potentsial [Russian students: identity, life strategies and civic potential]. Moscow: IEA RAS.

Tishkov, V.A., ed. 2011. Rossiiskaya natsiya: Stanovlenie i etnokul turnoe mnogoobrazie [Russian nation: formation and ethnocultural diversity]. Moscow: Nauka.

Tishkov, V.A., Filippova, E.I., eds. 2016. Kul'turnaya slozhnost' sovremennykh natsii [Cultural complexity of modern nations]. Moscow: Politicheskaya entsiklopediya. 